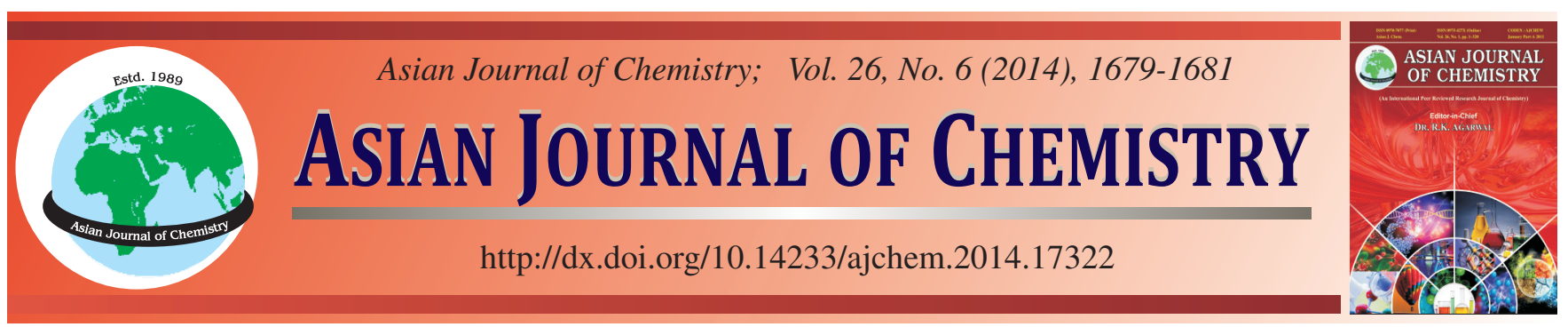

\title{
Effect of $\mathrm{Y}_{2} \mathrm{O}_{3}: \mathrm{Eu}^{3+}$ Particles on Fluorescence, Thermal and Mechanical Properties of Poly(methyl methacrylate) Composite $\dagger$
}

Meng Li, Yun Wu and BenHONG YANG*

Department of Chemistry and Materials Engineering, Hefei University, Hefei 230601, P.R. China

*Corresponding author: E-mail: yangbh@hfuu.edu.cn

\begin{abstract}
In order to obtain photoluminescence characteristics of poly(methyl methacrylate) (PMMA), $\mathrm{Y}_{2} \mathrm{O}_{3}: \mathrm{Eu}^{3+}$ particles are modified by silane coupling agent (KH-151) and introduced into poly(methyl methacrylate) via the in situ polymerization. $\mathrm{The}_{2} \mathrm{O}_{3}: \mathrm{Eu}^{3+} / \mathrm{PMMA}$ composites exhibit enhanced properties of strength, thermal stability and fluorescence comparing with poly(methyl methacrylate). In particular, the $\mathrm{Y}_{2} \mathrm{O}_{3}: \mathrm{Eu}^{3+} / \mathrm{PMMA}$ composite with $0.3 \mathrm{wt} \%$ content of $\mathrm{Y}_{2} \mathrm{O}_{3}: \mathrm{Eu}^{3+}$ exhibits the highest tensile strength of $55 \mathrm{MPa}$, suggesting its potential application in photoluminescence.
\end{abstract}

Keywords: $\mathrm{Y}_{2} \mathrm{O}_{3}: \mathrm{Eu}^{3+}$, Poly(methyl methacrylate), Particles, Polymerization.

\section{INTRODUCTION}

Metal oxide-polymer composites which combine the desired functionalities of both polymer matrix and metal oxide fillers have attracted much attention in recent years. Europiumdoped $\mathrm{Y}_{2} \mathrm{O}_{3}\left(\mathrm{Y}_{2} \mathrm{O}_{3}: \mathrm{Eu}^{3+}\right)$ is considered as an important fluorescent material owing to its good luminescent property with high chemical stability and acceptable atmospheric stability that give rise to many application areas, such as fluorescent lights, plasma display panel (PDP), cathode ray tubes (CRT) and field emission display $(\mathrm{FED})^{1,2}$. Hence, $\mathrm{Y}_{2} \mathrm{O}_{3}: \mathrm{Eu}^{3+}$ particles are usually introduced into polymer matrix to improve the fluorescent property of polymer.

Poly(methyl methacrylate) (PMMA) is an optically clear amorphous thermoplastic polymer with excellent impact strength and dimensional stability. Due to its favorable properties, PMMA is an excellent substitute for conventional inorganic glass in many applications. Herein, we choose PMMA as polymer base and synthesize $\mathrm{Y}_{2} \mathrm{O}_{3}$ : $\mathrm{Eu}^{3+} / \mathrm{PMMA}$ composites by in situ bulk polymerization. Their fluorescence, thermal and mechanical properties are investigated in details.

\section{EXPERIMENTAL}

$\mathrm{Y}_{2} \mathrm{O}_{3}: \mathrm{Eu}^{3+}$ particles were prepared according to the following procedure. Yttrium oxide and europium oxide were dissolved in dilute hydrochloric acid with constant stirring and then sodium hydroxide solution was added to adjust the $\mathrm{pH}$ value of the system to 13 . The mixture was dried at $160{ }^{\circ} \mathrm{C}$ in a vacuum oven for $6 \mathrm{~h}$ and then calcined at $900{ }^{\circ} \mathrm{C}$ for $4 \mathrm{~h}$. The final product was ground into powder and treated with the silane coupling agent $(\mathrm{KH}-151)$ under reflux for $4 \mathrm{~h}$ at $80{ }^{\circ} \mathrm{C}$.

$\mathrm{Y}_{2} \mathrm{O}_{3}: \mathrm{Eu}^{3+} / \mathrm{PMMA}$ composites were synthesized as follow: various amounts of $\mathrm{Y}_{2} \mathrm{O}_{3}:$ Eu $^{3+}$ particles $0,0.1,0.3,0.5,0.7$ and $0.9 \%$ (wt \%) were dispersed into methyl methacrylate monomer by sonicating. Polymerization of this mixture was initiated by azodiisobutyronitrile (AIBN) under constant stirring at $80^{\circ} \mathrm{C}$ for $0.5 \mathrm{~h}$. Afterwards, the solution in the flask was poured into a glass mould and kept at $50{ }^{\circ} \mathrm{C}$ for $5 \mathrm{~h}$ and subsequently at $100{ }^{\circ} \mathrm{C}$ for $2 \mathrm{~h}$ in an electric oven.

\section{RESULTS AND DISCUSSION}

FTIR spectra of modified $\mathrm{Y}_{2} \mathrm{O}_{3}: \mathrm{Eu}^{3+}$ particles (a) and $\mathrm{Y}_{2} \mathrm{O}_{3}: \mathrm{Eu}^{3+} / \mathrm{PMMA}$ composite (b) are shown in Fig. 1. The absorption peaks between 3400 and $3450 \mathrm{~cm}^{-1}$ are associated with -OH groups, which are bonded onto the surface of $\mathrm{Y}_{2} \mathrm{O}_{3}: \mathrm{Eu}^{3+}$ particles. The characteristic peak of $\mathrm{C}=\mathrm{C}$ at 1620 $\mathrm{cm}^{-1}$ in Fig. 1(b) disappears, suggesting that PMMA chains graft onto $m-\mathrm{Y}_{2} \mathrm{O}_{3}: \mathrm{Eu}^{3+}$ particles successfully. Additionally, two characteristic bands of acetate groups centered at 1660 and $1260 \mathrm{~cm}^{-1}$ are attributed to the stretching vibrations of $\mathrm{C}=\mathrm{O}$ and $\mathrm{C}-\mathrm{O}$ in PMMA, respectively.

†Presented at The 7th International Conference on Multi-functional Materials and Applications, held on 22-24 November 2013, Anhui University of Science \& Technology, Huainan, Anhui Province, P.R. China 


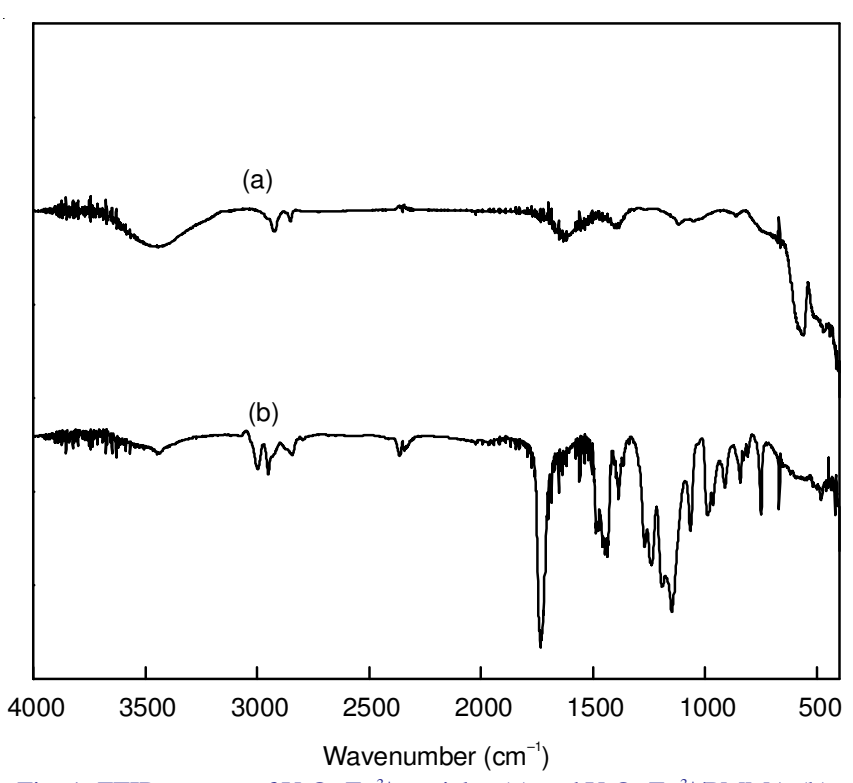

Fig. 1. FTIR spectra of $\mathrm{Y}_{2} \mathrm{O}_{3}: \mathrm{Eu}^{3+}$ particles (a) and $\mathrm{Y}_{2} \mathrm{O}_{3}: \mathrm{Eu}^{3+} / \mathrm{PMMA}$ (b)

Fig. 2 shows the fluorescence spectra of $\mathrm{Y}_{2} \mathrm{O}_{3}: \mathrm{Eu}^{3+} / \mathrm{PMMA}$ composites after excitation at $254 \mathrm{~nm}$. All fluorescence spectra of $\mathrm{Y}_{2} \mathrm{O}_{3}: \mathrm{Eu}^{3+} / \mathrm{PMMA}$ composites show red emission centered at $605-620 \mathrm{~nm}$ which is assigned to $4 \mathrm{f}$-electronic transitions of $\mathrm{Eu}^{3+}\left({ }^{5} \mathrm{D}_{0}{ }^{-} \mathrm{F}_{2}\right.$ electric dipolar transition) ${ }^{3,4}$. Additionally, their fluorescence intensities increase with increasing $\mathrm{Y}_{2} \mathrm{O}_{3}: \mathrm{Eu}^{3+}$ content.

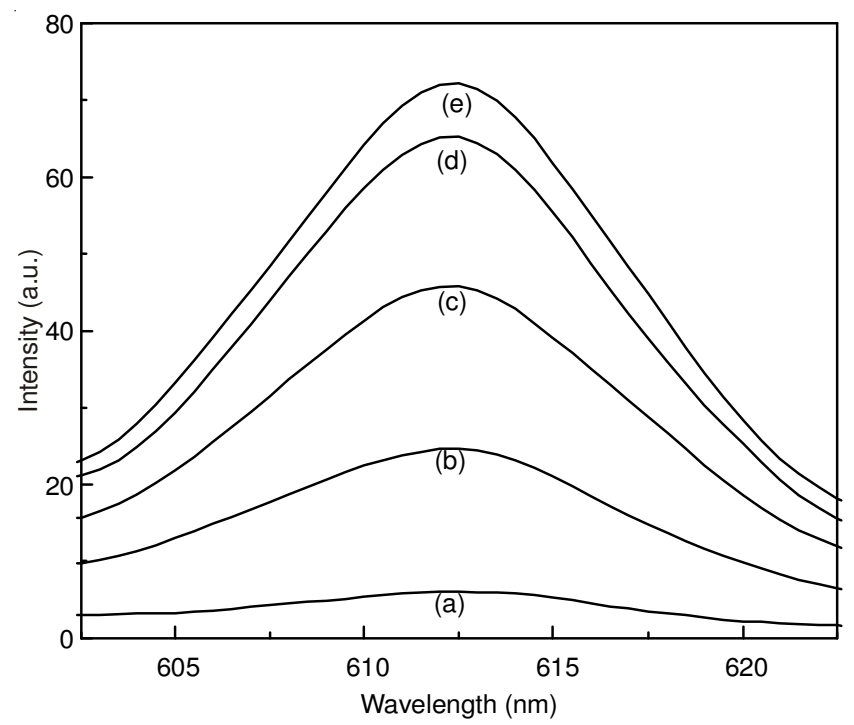

Fig. 2. Fluorescence spectra measured under the $254 \mathrm{~nm} \mathrm{UV}$ excitation of $\mathrm{Y}_{2} \mathrm{O}_{3}: \mathrm{Eu}^{3+} / \mathrm{PMMA} 0.1 \%$ (a), $\mathrm{Y}_{2} \mathrm{O}_{3}: \mathrm{Eu}^{3+} / \mathrm{PMMA} 0.3 \%$ (b), $\mathrm{Y}_{2} \mathrm{O}_{3}: \mathrm{Eu}^{3+} / \mathrm{PMMA} 0.5 \%$ (c), $\mathrm{Y}_{2} \mathrm{O}_{3}: \mathrm{Eu}^{3+} / \mathrm{PMMA} 0.7 \%$ (d) and $\mathrm{Y}_{2} \mathrm{O}_{3}: \mathrm{Eu}^{3+} / \mathrm{PMMA} 0.9 \%$ (e)

Fig. 3 shows the dependence of the tensile strength of $\mathrm{Y}_{2} \mathrm{O}_{3}: \mathrm{Eu}^{3+} / \mathrm{PMMA}$ composites on $\mathrm{Y}_{2} \mathrm{O}_{3}: \mathrm{Eu}^{3+}$ contents. The result shows that the tensile strength first increases to a maximum of $55 \mathrm{MPa}$ when $\mathrm{Y}_{2} \mathrm{O}_{3}: \mathrm{Eu}^{3+}$ content increase to $0.3 \%$, then it starts to decrease as $\mathrm{Y}_{2} \mathrm{O}_{3}: \mathrm{Eu}^{3+}$ content increasing. It should be noted that all composites exhibit better mechanical performance than pure PMMA. The highest tensile strength of $\mathrm{Y}_{2} \mathrm{O}_{3}: \mathrm{Eu}^{3+} / \mathrm{PMMA}$ composites measured in this study are $38 \%$ higher than pure PMMA.

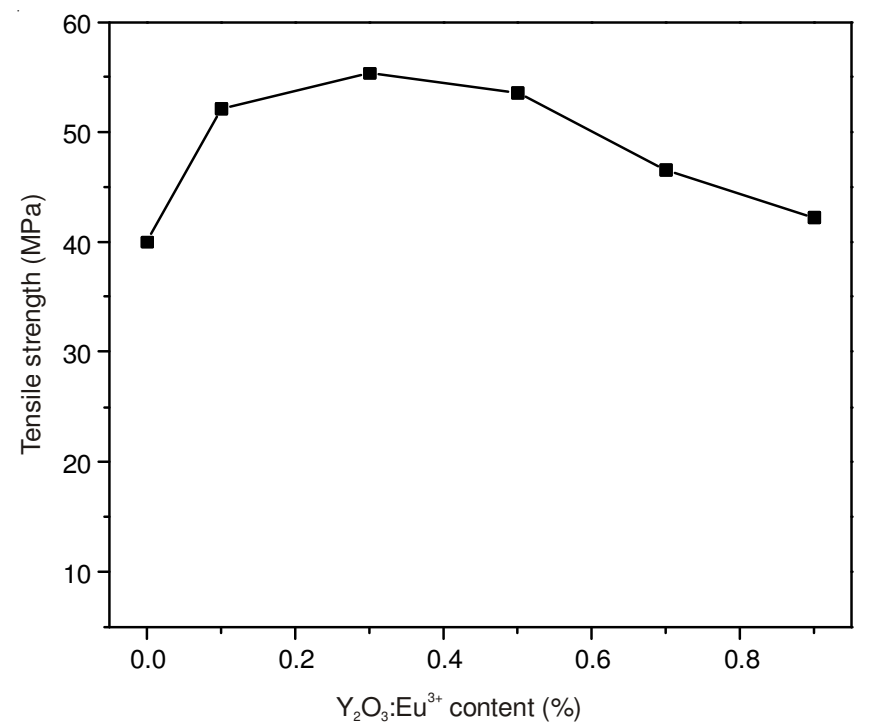

Fig. 3. Effect of $\mathrm{Y}_{2} \mathrm{O}_{3}: \mathrm{Eu}^{3+}$ content on the tensile strength of $\mathrm{Y}_{2} \mathrm{O}_{3}: \mathrm{Eu}^{3+}$ / PMMA composites

Thermogravimetric analysis (TGA) of pure PMMA and $\mathrm{Y}_{2} \mathrm{O}_{3}: \mathrm{Eu}^{3+} / \mathrm{PMMA}$ composites are shown in Fig. 4. Apparently, thermal stability of the composite is significantly improved by incorporating $\mathrm{Y}_{2} \mathrm{O}_{3}: \mathrm{Eu}^{3+}$ particles into PMMA matrix. They are thermally stable up to $180^{\circ} \mathrm{C}$ and start to degrade in threesteps. The thermal degradation of the $\mathrm{Y}_{2} \mathrm{O}_{3}: \mathrm{Eu}^{3+} / \mathrm{PMMA}$ composites shifts to higher temperature comparing with pure PMMA, especially at high content of $\mathrm{Y}_{2} \mathrm{O}_{3}: \mathrm{Eu}^{3+}(0.5 \mathrm{wt} \%)$, confirming the enhancement of thermal stability of PMMA by $\mathrm{Y}_{2} \mathrm{O}_{3}: \mathrm{Eu}^{3+}$ particles.

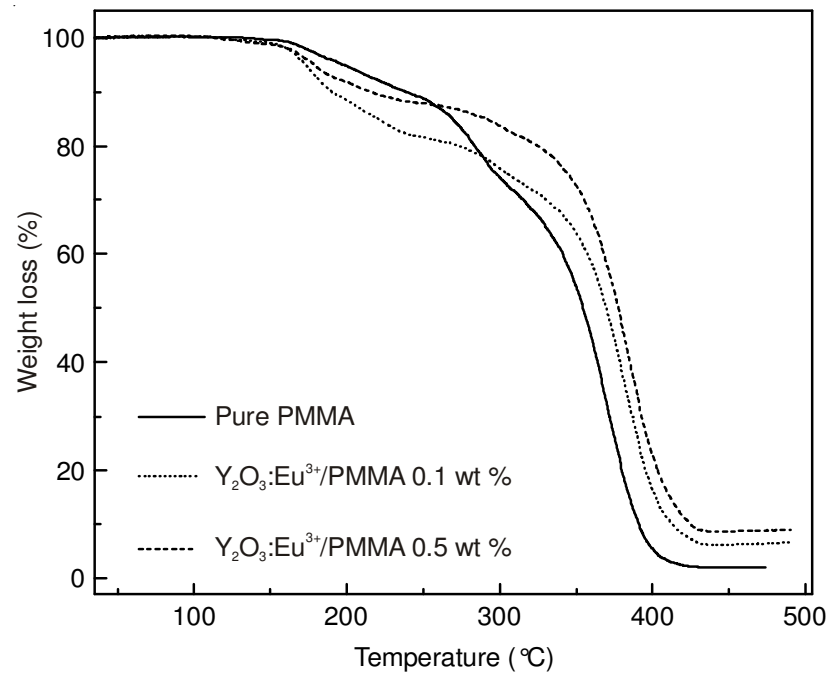

Fig. 4. TGA curves of pure PMMA and $\mathrm{Y}_{2} \mathrm{O}_{3}: \mathrm{Eu}^{3+} / \mathrm{PMMA}$ composites

\section{Conclusion}

Red emitting $\mathrm{Y}_{2} \mathrm{O}_{3}: \mathrm{Eu}^{3+} / \mathrm{PMMA}$ composites with excellent thermal stability and tensile strength were synthesized by in situ bulk polymerization. Tensile strength and TGA data suggest that mechanical and thermal stability are dependent on $\mathrm{Y}_{2} \mathrm{O}_{3}: \mathrm{Eu}^{3+}$ content. The optimized $\mathrm{Y}_{2} \mathrm{O}_{3}: \mathrm{Eu}^{3+} / \mathrm{PMMA} \mathrm{com-}$ posites with favorable luminescent and mechanical properties holds promising as a new class of fluorescent material. 
ACKNOWLEDGEMENTS

The authors are grateful for the financial support from the Natural Science Foundation of Anhui Educational Department (No. KJ2011A247), the Natural Science Foundation of Anhui Province (No. 1208085MB24) and the Natural Science Foundation of Hefei University (No. 11KY01ZR). This work is also supported by the Open Foundation of Anhui Province Key Laboratory of Environment-friendly Polymer Materials.

\section{REFERENCES}

1. R. Schmechel, M. Kennedy, H. von Seggern, H. Winkler, M. Kolbe, R.A. Fischer, L. Xaomao, A. Benker, M. Winterer and H. Hahn, J.Appl. Phys., 89, 1679 (2001).

2 R.M. Krsmanovic, Z. Antic, M.G. Nikolic, M. Mitric and M.D. Dramicanin, Ceram. Int., 37, 525 (2011).

3. R. Pazik, D. Hreniak, W. Strek, V.G. Kessler and G.A. Seisenbaeva, J. Alloys Comp., 451, 557 (2008).

4. M.N. Luwang, R.S. Ningthoujam, S.K. Srivastava and R.K. Vatsa, J. Am. Chem. Soc., 132, 2759 (2010). 